\title{
Cross-cultural adaptation and validation of the Protective Nursing Advocacy Scale for Brazilian nurses ${ }^{1}$
}

\author{
Jamila Geri Tomaschewski-Barlem² \\ Valéria Lerch Lunardi ${ }^{3}$ \\ Edison Luiz Devos Barlem ${ }^{4}$ \\ Rosemary Silva da Silveira ${ }^{3}$ \\ Graziele de Lima Dalmolin ${ }^{4}$ \\ Aline Marcelino Ramos ${ }^{5}$
}

Objective: to adapt culturally and validate the Protective Nursing Advocacy Scale for Brazilian nurses. Method: methodological study carried out with 153 nurses from two hospitals in the South region of Brazil, one public and the other philanthropic. The cross-cultural adaptation of the Protective Nursing Advocacy Scale was performed according to international standards, and its validation was carried out for use in the Brazilian context, by means of factor analysis and Cronbach's alpha as measure of internal consistency. Results: by means of evaluation by a committee of experts and application of pre-test, face validity and content validity of the instrument were considered satisfactory. From the factor analysis, five constructs were identified: negative implications of the advocacy practice, advocacy actions, facilitators of the advocacy practice, perceptions that favor practice advocacy and barriers to advocacy practice. The instrument showed satisfactory internal consistency, with Cronbach's alpha values ranging from 0.70 to 0.87. Conclusion: it was concluded that the Protective Nursing Advocacy Scale Brazilian version, is a valid and reliable instrument for use in the evaluation of beliefs and actions of health advocacy, performed by Brazilian nurses in their professional practice environment.

Descriptors: Health Advocacy; Nursing; Ethics, Nursing; Validation Studies.

\footnotetext{
${ }^{1}$ Paper extracted from doctoral dissertation "The practice of patient advocacy by nurses: a Foucauldian perspective", presented to Universidade Federal do Rio Grande, Rio Grande, RS, Brazil. Supported by Conselho Nacional de Desenvolvimento Científico e Tecnológico (CNPq), Brazil, process no 474761/2012-6.

${ }^{2}$ PhD, Assistant Professor, Escola de Enfermagem, Universidade Federal do Rio Grande, Rio Grande, RS, Brazil. Scholarship holder from Fundação de Amparo à Pesquisa do Estado do Rio Grande do Sul (FAPERGS), Brazil.

${ }^{3} \mathrm{PhD}$, Associate Professor, Escola de Enfermagem, Universidade Federal do Rio Grande, Rio Grande, RS, Brazil.

${ }^{4}$ PhD, Professor, Escola de Enfermagem, Universidade Federal do Rio Grande, Rio Grande, RS, Brazil.

${ }^{5}$ Master's student, Universidade Federal do Rio Grande, Rio Grande, RS, Brazil. Scholarship holder from Conselho Nacional de Desenvolvimento Científico e Tecnológico (CNPq), Brazil.
}

Corresponding Author:

Jamila Geri Tomaschewski Barlem

Universidade Federal do Rio Grande. Escola de Enfermagem

Rua General Osório, s/n

Centro

CEP: 96201-900, Rio Grande, RS, Brasil

E-mail: jamila_tomaschewski@hotmail.com
Copyright () 2015 Revista Latino-Americana de Enfermagem This is an Open Access article distributed under the terms of the Creative Commons Attribution Non-Commercial License (CC BY-NC).

This license lets others distribute, remix, tweak, and build upon your work non-commercially, and although their new works must also acknowledge you and be non-commercial, they don't have to license their derivative works on the same terms. 


\section{Introduction}

The practice of health advocacy by nurses has its roots in the 1970s, emerging from social movements that contributed to the rejection of paternalistic health practices, by consumers of healthcare and to meet the requirements of the exercise of their autonomy in situations of clinical decision-making about care, during their processes of health and disease ${ }^{(1-2)}$. From 1980 , health advocacy was recognized in the practice environments of the nurses as an inherent element of the professional ethics in nursing, due to the close relationship between nurse and patient and the length of stay of these professionals in the health facilities ${ }^{(3-4)}$.

On the international scene, investigations performed with nurses from different contexts showed that health advocacy may consist of multidimensional behaviors and is associated, mainly, to the recognition of the role of health advocacy by nurses, considering their beliefs and actions in relation to the care provided by them to the patients ${ }^{(5-6)}$. Furthermore, health advocacy has been defined as part of the nurses' efforts to promote the welfare and interests of their patients, ensuring they are aware of their rights and have access to information for decision making ${ }^{(6-9)}$. However, it is emphasized that the challenge of defining and describing the actions of nurses in health advocacy constitutes a complex task, because these actions are not static and fixed, but influenced by particular characteristics of individuals, organizations, relationships, medical conditions and performance environments ${ }^{(10)}$.

Empirical studies suggest that there are still contradictions and different interpretations about health advocacy, particularly between nurses and researchers in nursing(11). In this way, gaps and difficulties in interpreting the concept of health advocacy in nursing may be the main barriers to its exercise in different healthcare environments and for progress of research in this area.

In this sense, the Protective Nursing Advocacy Scale (PNAS) was developed for use in quantitative studies aiming to measure beliefs and actions in health advocacy in nursing, in order to fill the gaps related to its concept ${ }^{(12)}$. This instrument was validated in the United States, with a sample of medical-surgical nurses. It includes questions encompassing actions performed by nurses in the practice of health advocacy, its possible consequences in the work environment, the influence of knowledge and personal values of the nurses to work in health advocacy, as well as the facilitators and barriers to the practice of health advocacy in nursing(12).

In the Brazilian context, there are no studies on the practice of health advocacy by nurses. Consequently, it is necessary to develop instruments that may contribute to the recognition of health advocacy actions performed by nurses, besides contributing to the strengthening of this practice in their work environment. In this fashion, this study is justified by the need to analyze the practice of health advocacy within the context of the Brazilian nurses, exploiting their beliefs and actions in this practice, as well as its possible barriers, facilitators and implications.

Accordingly, the objective of this study was to adapt culturally and validate the Protective Nursing Advocacy Scale for Brazilian nurses.

\section{Method}

This is a methodological study, which aimed at performing the cultural adaptation of the PNAS instrument, in accordance with international standards(13), and its validation for use in the Brazilian context. It involved the translation and back-translation of the original version in English into Portuguese of Brazil, its validity of face and content, as well as the description of the psychometric properties related to the validity and reliability of the construct evaluated by factor analysis and Cronbach's alpha.

The journal responsible for the copyright of the instrument, as well as the author of the instrument, Robert Hanks, through electronic contact, authorized the cross-cultural adaptation of the PNAS instrument. The ethical aspects were respected, according to the recommendations of the Resolution number 466/12, of the National Health Council, with the approval of the Research Ethics Committee (Opinion number 97/2013).

\section{Original instrument}

The original PNAS consists of 43 questions, answered by means of a Likert-type frequency scale of five points, using 1 for "strongly disagree", 2 for "partially disagree", 3 to "neither agree nor disagree" 4 to "partially agree" and 5 for "strongly agree".

Based on the application of the PNAS in a sample of 419 medical-surgical nurses in the United States, 37 questions have been validated into four constructs: acting as an advocate, which reflects actions of nurses when advocate in health for patients, work situations 
and advocacy actions, which reflects possible health advocacy consequences in the work environment, environment and educational influences, which includes items measuring the influence of knowledge and internal environment of nurses, such as personal values, beliefs and confidence to work in health advocacy, support and barriers to advocacy, which consists of items indicating the facilitators and barriers to health advocacy in nursing, including the work environment as a whole ${ }^{(12)}$.

\section{Cross-cultural adaptation: validation of face and content of the instrument}

The six steps aiming at the complete adaptation of the instrument were followed, maximizing of the semantic attainment, idiomatic, experiential and conceptual aspects between the original instrument and the adapted instrument: initial translation, synthesis of translations, back-translation, experts committee, pretest and revision of the process of adaptation by the researchers ${ }^{(13)}$.

In the first stage, initial translation, the PNAS scale was sent to two bilingual translators, independently, in order to translate it from English into Portuguese. These translators had different profiles, so that one of them was familiar with translations of health-related materials and aware of the concepts to be analyzed in the scale; whereas the other one was not informed about the objectives of the translation and had no experience with translations in the healthcare area ${ }^{(13)}$.

After the initial translation, the report originated from the synthesis of the translations was submitted to the backtranslation process ${ }^{(13)}$. At this stage, the scale produced from the synthesis of the translations was back-translated from Portuguese into English by two translators. These translators were not informed on the objectives of the translation and had no experience in translations in the healthcare area, seeking to avoid wrong meanings in the items of the translated scale. After compilation of the two documents resulting from back-translation, it was carried out an additional backtranslated version of the scale(13).

In order to develop the pre-final version of the PNAS for field-testing, the back-translated version of the scale was submitted to a committee of experts, through individual meetings. This committee, composed by four professors, PhDs in nursing, of a public university in the South region of Brazil, with extensive experience in the subject on ethics in nursing, evaluated the semantic, cultural, idiomatic and conceptual equivalences, as well as the face validity of the scale, approving it for use in the pre-test. The face validity aimed to verify whether the questions of the scale presented form and vocabulary appropriate to measurement purpose ${ }^{(13-14)}$.

In the pre-test stage, the version validated by the experts committee was applied to 30 nurses, students of master's or doctorate in nursing at a public university in the South region of Brazil, which agreed to participate in this process. The pre-test aimed to ensure the content validity of the scale, aiming to confirm that its items represent the desired content. The scale was applied individually, so that respondents reported their difficulties and skills in completing it and suggested changes in the writing of the questions, if necessary ${ }^{(13)}$.

After finalization of the pre-test, the researchers responsible for the cross-cultural adaptation of the scale carried out a review of the adaptation process. This review aimed to make changes on the scale, in order to facilitate its understanding and enable, therefore, the application of the scale in the sample selected for the quantitative stage of the study(13).

\section{Local and subjects of the study}

The application of the final version of the data collection instrument was performed in two hospitals in the South of Brazil, one public and the other philanthropic. The first hospital named "H1", is characterized as a public university hospital, that assists exclusively users of the Brazilian Unified Health System (SUS). It has 195 beds and 67 nurses with weekly working hours of $30 \mathrm{~h}$. The second hospital, named "H2", is characterized as a philanthropic organization, assisting patients of SUS and patients with private health insurance. It comprises three distinct hospitals: a general hospital, a hospital of cardiology and oncology, and a psychiatric hospital, comprising 644 beds in total. It has 174 nurses with weekly working hours of 36 hours or 40 hours.

The criteria for selection of the respondents were limited to be a nurse, act professionally in the respective hospitals, and have availability and interest to respond to data collection instrument. For the selection of respondents, it was used the nonprobabilistic sampling method and by convenience, so that all nurses working in these institutions, which were in their places of work, during the data collection period were invited to participate in the survey ${ }^{(14)}$. By means of statistical procedure, the sample was estimated in 150 respondents $^{(15)}$. 


\section{Data collection}

It was adopted as delivery procedure for the application of the data collection instrument, visits to the two selected hospitals so that nurses were invited to participate in the study on their work place and at their work shift. The instrument was delivered directly to respondents in an envelope without identification, together with the Free and Informed Consent Form (IC). Together with the distribution of the instrument and consents, it was performed the scheduling of their gathering by setting a maximum of three attempts to each distinct location for collection of the previously delivered instrument.

Data collection instrument was delivered to 198 nurses and 165 (83.33) were recovered. Of these, 12 were excluded because they were not properly completed. The final sample included 153 respondents.

\section{Validation of the instrument's construct}

Following the application of the data collection instrument in the selected sample, the construct validation was carried out by factor analysis and verification of internal consistency by using the Cronbach's alpha. To perform statistical tests, it was used the SPSS statistical software (Statistical Package for Social Sciences), version 22.0, which facilitated the organization of data in tables and allowed a better visualization of the results and their interpretation.

Factor analysis was performed in order to reduce and summarize the data, aiming at the formation of factors. The principal component analysis was defined as extraction method, by applying the Varimax orthogonal rotation to better discriminate the relevance of the variables to the components identified. The formation of the factors followed two criteria: degree of association among the variables, found using the factor loadings (>.400); and their degree of subjectivity. Nevertheless, the Cronbach's alpha was used to assess the reliability of the instrument to check the consistency of different characteristics of each factor measured by the questions of the instrument ${ }^{(14)}$.

\section{Results}

With regard to the face validity of the instrument, the experts committee indicated consensus among all the items of the scale, evaluating them as relevant and ensuring their semantic, cultural, idiomatic and conceptual consistency. There was the understanding of all items, in the way that these were formulated, so that the questions suffered few changes, merely regarding to their form of writing.

In question 41, "I am not an effective advocate because I have been suffering from professional exhaustion (Burnout)", it was also suggested adding the term "moral suffering", in view of the strong relationship between this phenomenon, the Burnout, and health advocacy ${ }^{(15)}$. Thus, question 41 was proposed as follows: "I am not an effective advocate because I have been suffering from professional exhaustion (Burnout) and/ or moral suffering". In addiction, in the Likert scale, the options "partially disagree" and "partially agree" were replaced respectively by "disagree more than agree" and "agree more than disagree".

The other instruction received was to ensure that nurses had knowdledge, even though superficially, about the term health advocacy, considering its limited use in Brazil. Therefore, along with the instructions for the completing the instrument, a brief definition of the health advocacy term was inserted based on the literature ${ }^{(6-9,12)}$. Regarding to the translation of the scale title into Portuguese, it was set up the Patient Advocacy Scale for Nurses or Protective Nursing Advocacy Scale (PNAS) - Brazilian version (PNAS-BV).

As regards the content validity, the pre-test carried out with 30 nurses and students of master's and doctoral programs, confirmed that the scale items represented the analyzed content, consequently, it was not necessary any change in the writing of the questions. When they were asked about the difficulties and facilities in completing the instrument, 24 participants considered the items of the instrument as easy to understand. However, six participants demonstrated little difficulties, mainly related to the repetition of certain words and ideas. The time for completing the instrument ranged from 12 to 20 minutes.

Regarding the characteristics of the sample studied, it was observed that the average age of the 153 nurses was 33.13 years and most were females (89.5\%). Of the 153 nurses, 51 (33.3\%) worked in the hospital " $\mathrm{H} 1$ " and $102(66.7 \%)$ in the hospital "H2". It was found an average of professional training time of 7 years (7.04) and an average of professional performance time of 6 years (6.49).

As regards the validity of the construct, the 43 questions of the instrument were submitted to exploratory factor analysis (between clusters), in order to verify the discriminant validity of the instrument. The first cluster 
suggested the formation of twelve constructs, making difficult the categorization, in accordance with the context proposed. Accordingly, there was the process of gradual exclusion of every question presenting low correlation rates in its cluster or non-adherence to the conceptually formed constructs, in order to facilitate the grouping of the questions, considering factor loadings lower than 0.400 as cutoff.

To the extent that questions were eliminated and the constructs became defined, the pentafatorial formation was adopted as extraction solution. At the end of this analysis, 22 questions were excluded from the instrument because they achieved low factor loadings (lower than 0.400 ) or they formed isolated clusters (consisting of a single question), and a question was excluded for not presenting conceptual coherence with the proposed cluster. The five dimensions of the instrument explain the variation of $66.27 \%$ in relation to the original questions, representing a suitable degree of data synthesis, which facilitates the interpretation.

Hence, in its final version, the instrument consisted of 20 items and presented five constructs: negative implications of the advocacy practice, advocacy actions, facilitators of the advocacy practice, perceptions that favor advocacy and barriers to advocacy practice. Figure 1 shows the definition of each construct formed.

The reliability of the five constructs of the instrument was evaluated using the Cronbach's alpha calculation. The instrument presented Cronbach's alpha value of 0.78 , and the coefficients of the five constructs ranged from 0.70 to 0.87 . Table 1 shows the factor loadings of each construct, according to their formation on the factors, explained variance and Cronbach's alpha values.

\begin{tabular}{|l|l|}
\hline Construct & Definition of the construct \\
\hline $\begin{array}{l}\text { Negative implications of the } \\
\text { advocacy practice }\end{array}$ & $\begin{array}{l}\text { Consequences of the advocacy practice that can lead nurses to be accused of insubordination and suffer loss } \\
\text { of professional reputation, and may even be rotulated as awful co-workers, lose their jobs and experience } \\
\text { disturbances in their personal lives }{ }^{(16)}\end{array}$ \\
\hline Advocacy actions & $\begin{array}{l}\text { Multidimensional actions of nurses to advocate for patients, varying according to different clinical situations, } \\
\text { environments and relationships }{ }^{(5-6)}\end{array}$ \\
\hline $\begin{array}{l}\text { Facilitators of the advocacy } \\
\text { practice }\end{array}$ & $\begin{array}{l}\text { Characteristics and skills of nurses that can facilitate the practice of patient advocacy, such as situations in which } \\
\text { nurses present a higher sense of confidence resulting from their professional self-worth }\end{array}$ \\
\hline $\begin{array}{l}\text { Perceptions that favor advocacy } \\
\text { practice }\end{array}$ & $\begin{array}{l}\text { Perceptions of nurses in relation to advocacy and the care they provide to patients, which can improve their } \\
\text { performance in the workplace }\end{array}$ \\
\hline $\begin{array}{l}\text { Barriers to the advocacy } \\
\text { practice }\end{array}$ & $\begin{array}{l}\text { Barriers that may prevent nurses from fully performing their role as patient advocates, besides contributing to the } \\
\text { non-perception of their role in advocacy and so that they may have difficulties in decision-making in their work }{ }^{(16)}\end{array}$ \\
\hline
\end{tabular}

Figure 1 - Definition of the constructs formed. Rio Grande, RS, Brazil, 2014

Table 1 - Exploratory factor analysis (Varimax rotation). Rio Grande, RS, Brazil, 2014

\begin{tabular}{|c|c|c|c|c|c|c|}
\hline Questions & Cluster & F1 & F2 & F3 & F4 & F5 \\
\hline \multicolumn{7}{|l|}{ Negative implications of the advocacy practice } \\
\hline q30 Can be risky for my job to act as a patient advocate & .644 & .743 & 0.04 & -.222 & -.056 & .198 \\
\hline $\begin{array}{l}\text { q31 Nurses who speak for the patients may suffer retaliation from their } \\
\text { employers }\end{array}$ & .641 & .778 & -.033 & .081 & .134 & .097 \\
\hline $\begin{array}{l}\text { q32 I can be punished by the employer for my actions when I inform patients } \\
\text { about their rights }\end{array}$ & .701 & .812 & .014 & .011 & -.095 & .181 \\
\hline $\begin{array}{l}\text { q33 Nurses who speak on behalf of vulnerable patients may be labeled as } \\
\text { troublemakers by the employers }\end{array}$ & .715 & .824 & -.032 & -.016 & .136 & .126 \\
\hline $\begin{array}{l}\text { q34 When nurses inform and teach patients about their rights in the clinical } \\
\text { environment. they can put their job at risk }\end{array}$ & .690 & .820 & .041 & .094 & .009 & -.086 \\
\hline \multicolumn{7}{|l|}{ Advocacy actions } \\
\hline q5 I am acting on behalf of the patient when I'm acting as his/her advocate & .591 & -.092 & .748 & .081 & .131 & .019 \\
\hline q6 I am speaking on behalf of the patient when I'm acting as his/her advocate & .811 & .012 & .899 & .044 & .013 & .026 \\
\hline q7 I am acting as the voice of the patient when I am advocating for the patient & .766 & .024 & .861 & .149 & -.036 & -.003 \\
\hline q8 I am acting as a representative of the patient when I act as his/her advocate & .565 & .073 & .699 & .149 & .212 & -.052 \\
\hline \multicolumn{7}{|l|}{ Facilitators of the advocacy practice } \\
\hline q19 I can be a better patient advocate because I have more self-confidence & .517 & .115 & .299 & .640 & .064 & .017 \\
\hline $\begin{array}{l}\text { q20 Nurses who are committed to providing good care to patient are better } \\
\text { patient advocates }\end{array}$ & .754 & .036 & -.041 & .851 & .167 & .006 \\
\hline $\begin{array}{l}\text { q21 Greater dedication to nursing increases the ability of nurses to be a patient } \\
\text { advocate }\end{array}$ & .714 & -.033 & .092 & .832 & .109 & .028 \\
\hline
\end{tabular}


Table 1 - (continuation)

\begin{tabular}{|c|c|c|c|c|c|c|}
\hline Questions & Cluster & F1 & F2 & F3 & F4 & F5 \\
\hline $\begin{array}{l}\text { q22 Higher qualification in nursing improves the effectiveness of nurses in patient } \\
\text { advocacy }\end{array}$ & .705 & -.075 & .148 & .811 & .135 & -.030 \\
\hline \multicolumn{7}{|l|}{ Perceptions that favor advocacy practice } \\
\hline $\begin{array}{l}\text { q4 Nurses who understand the benefits of patient advocacy are better patient } \\
\text { advocates }\end{array}$ & .584 & -.186 & .394 & .398 & .439 & -.207 \\
\hline $\begin{array}{l}\text { q26 Nurses who provide information to patients about their care are acting as } \\
\text { their advocates }\end{array}$ & .612 & -.094 & .139 & .180 & .737 & .090 \\
\hline q27 Patients have varying degrees of ability to defend themselves & .566 & .180 & .061 & .107 & .719 &.-042 \\
\hline q28 Vulnerable patients need my protection in harmful situations & .671 & 0.66 & .188 & .106 & .785 & -.069 \\
\hline \multicolumn{7}{|l|}{ Barriers to the advocacy practice } \\
\hline $\begin{array}{l}\text { q41 I am not an effective advocate because I hav been suffering from } \\
\text { professional exhaustion (Burnout) and/or moral suffering }\end{array}$ & .644 & .323 & -.069 & .086 & -.026 & .726 \\
\hline $\begin{array}{l}\text { q42 Because I do not like working as a nurse, I have less will to act as a patient } \\
\text { advocate }\end{array}$ & .719 & .059 & .121 & .044 & .031 & .835 \\
\hline q43 I lack dedication to the nursing profession to act as a patient advocate & .644 & .079 & -.079 & -.108 & -.063 & .785 \\
\hline Initial Eigenvalue & & 4.35 & 3.72 & 2.08 & 1.71 & 1.38 \\
\hline$\%$ explained variation - rotated $(66.27 \%)$ & & 21.77 & 18.62 & 10.40 & 8.54 & 6.9 \\
\hline Cronbach's alpha (instrument 0.78 ) & & 0.87 & 0.84 & 0.81 & 0.70 & 0.70 \\
\hline \multicolumn{7}{|l|}{ Kaiser-Meyer-Olkin Measure of Sampling Adequacy $(\mathrm{KMO}=0.76)$} \\
\hline Bartlet test: Chi-square $=1245.737$ & & & & & & \\
\hline
\end{tabular}

\section{Discussion}

As evidenced in the results, the application of the PNASBV to the nurses of two hospitals presented five constructs that, in relation to the structure and concept definition, showed minor differences when compared to the results obtained in the validation study of the original instrument ${ }^{(12)}$, with tetrafatorial solution. However, by considering the theoretical basis of the health advocacy performed by nurses in their professional practice environment ${ }^{(6-9)}$, the instrument validated in this research presented theoretical adherence, highlighting five dimensions associated with health advocacy practice by nurses. It is noteworthy also that the Brazilian version is the first to become available, so it may not be found in the literature other versions of the instrument in other countries.

In the original PNAS, 37 questions were validated into four constructs: acting as an advocate, work situations and advocacy actions, environment and educational influences and support and barriers for the $\operatorname{advocacy}^{(12)}$. In the instrument validated for the Brazilian context, 20 questions were validated in five constructs: negative implications of the advocacy practice, advocacy actions, facilitators of the advocacy practice, perceptions that favor advocacy practice and barriers to the advocacy practice. The differences between the studies show peculiarities in the application of the PNAS in different environments and cultures, demonstrating that the way by which the nurses perform the health advocacy may vary in different contexts.
Regarding the constructs, the first construct of the PNAS-BV, negative implications of the advocacy practice, is composed of the same items that form the second subscale of the original PNAS(12) "work situation and advocacy actions". Although the positive effects of the advocacy are widely recognized by ensuring that rights, values and interests of the patient are protected and preserved, nurses may face several negative consequences of health advocacy practice, because of the ethical problems encountered in daily work ${ }^{(16)}$. In this way, the items of this construct correspond to the findings in the literature, considering that the act of advocating in favour of the patient's health, in the nursing practice environment, may result in risks for nurses, which are labeled as troublemakers by their coworkers and employers or end up losing their jobs ${ }^{(17)}$.

Nevertheless, the construct actions in advocacy is directly related to the subscale "acting as advocate" of the original PNAS(12), which is represented by actions performed by nurses as patients' advocates. However, in the original PNAS, this subscale also contains items that reflect the perceptions of nurses regarding the care they provide to patients and the advocacy practice, while in the PNAS-BV, the items that make up this construct are restricted only to the actions performed by the nurses.

The construct facilitators of the advocacy practice includes items related to personal and professional characteristics of the nurses, which can be considered the main facilitators of the advocacy practice in the workplace $^{(3,18)}$. This construct corresponds to the subscale 
"environment and educational influences", proposed by the original PNAS, also made up of items that relate to the use of personal and professional experience to act as an advocate and to the internal environment of the nurses, including the intrinsic characteristics such as trust, personal values and beliefs $^{(12)}$.

This subscale is of utmost importance for understanding the practice of law by nurses, since, although there is desire and need to advocate for the rights and interests of patients, often the nurses are not adequately trained to the advocacy practice, as in the absence of understanding of ethical situations or personal and technical limitations ${ }^{(3,12,17)}$.

The fourth construct, perceptions that favor advocacy practice, may be linked to some circumstances that act as a "trigger" so that the exercise of the patient's health advocacy is expressed, such as: the patient's vulnerability, the professional responsibility and the moral obligation of nurses(19). Thus, it is observed that the advocacy practice may result from the own perceptions of nurses regarding the care provided to patients. These perceptions include the sense of professional responsibility, recognition of the health advocacy benefits by the nurses, establishment of an appropriate relationship with the patients and the possible confrontations with institutional interests, resulting from informing the patients on their rights and, contributing so that they perform decision-making with autonomy(2).

Regarding the last construct, barriers to the advocacy practice, it was observed that the validated items include barriers that discourage nurses to act according to their knowledge and values, such as, for example, in situations recognized as dissatisfaction with their job and with their chosen career, Burnout and/ or moral suffering, making difficult the nurses to fully realize their role as patient advocates ${ }^{(19)}$. In this way, by choosing not to face the barriers that may prevent the advocacy practice, nurses are not abandoning the profession, but are turning away from their values, beliefs and, finally, the ideals of the profession(19).

In the original PNAS(12), the "support and barriers for advocacy" subscale was validated, which differs from the construct of this study, since the items related to support for the advocacy were validated in the third construct, facilitators of the advocacy practice, which are related only to personal values and the professional training of nurses. Thus, Brazilian nurses seem to understand the values and professional training as key sources of support for advocacy actions. In addiction, in the original
PNAS, the "environment and educational influences" and "support and barriers to advocacy" subscales have some similarities among their items, considering that they were constituted by questions that reflected the internal characteristics of nurses, contributing to their capacity to advocate, such as confidence(12).

Regarding the reliability of the instrument, the results showed quite satisfactory rates, especially when compared to the validation of the original instrument ${ }^{(12)}$, thus ensuring the reliability of the validated instrument for further studies. The Cronbach's alpha value of the PNAS-BV was 0.78 and the coefficients of the five constructs ranged from 0.70 to 0.87 . This result is similar to the original PNAS, whose Cronbach's alpha value was 0.80 for the instrument and ranged from 0.93 to 0.70 in the four constructs ${ }^{(12)}$, representing high internal consistency among the responses.

\section{Conclusion}

The results show that the Protective Nursing Advocacy Scale - Brazilian version represents a valid and reliable instrument for the evaluation of beliefs and health advocacy actions by Brazilian nurses, contributing to guide the advocacy practice in nursing and providing bases for research in this area.

It was possible to identify five constructs that explain the practice of health advocacy by nurses in the Brazilian context: negative implications of the advocacy practice, advocacy actions, facilitators of the advocacy practice, perceptions that favor advocacy practice and barriers to the advocacy practice. The validation of the Portuguese version of the instrument is presented as an additional resource to be made available to researchers who aim to better understand the practice of health advocacy for nurses in numerous healthcare institutions in the Brazilian context.

As a limitation of this study, it is highlighted the absence of the PNAS adapted and validated to other countries, which prevented the establishment of comparisons. Finally, it is suggested the application of the instrument adapted by this research in other locations in Brazil, verifying whether there are, or not, significant differences affecting the understanding of the beliefs and health advocacy actions by Brazilian nurses.

\section{References}

1. Annas GJ. The patient rights advocate: can nurses effectively fill the role? Superv Nurse. 1974 Jul;5(7):20-5. 
2. Pavlish C, Ho A, Rounkle A. Health and human rights advocacy: perspectives from a Rwandan refugee camp. Nurs Ethics. 2012 Jul;19(4):538-49.

3. Hanks RG. The medical-surgical nurse perspective of advocate role. Nurs Forum. 2010 Apr-Jun;45(2):97-107. 4. Josse-Eklund $A$, Jossebo $M$, Sandin-Bojo AK, WildeLarsson B, Petzall K. Swedish nurses' perceptions of influencers on patient advocacy. Nurs Ethics. $2014 ; 21(6): 673-83$.

5. Bu X, Wu YB. Development and psychometric evaluation of the instrument: attitude toward patient advocacy. Res Nurs Health. 2008 Feb;31(1):63-75.

6. Vaartio $H$, Leino-Kilpi $H$, Suominen $T$, Puukka $P$. Nursing Advocacy in Procedural Pain Care. Nurs Ethics. 2009 May;16(3):340-62.

7. Ware LJ, Bruckenthal P, Davis GC, O'Conner-Von SK. Factors that influence patient advocacy by pain management nurses: results of the American society for pain management nursing survey. Pain Manag Nurs. 2011 Mar;12(1):25-32.

8. Cawley T, Mcnamara PM. Public health nurse perceptions of empowerment and advocacy in child health surveillance in West Ireland. Public Health Nurs. 2011 Mar-Apr;28(2):150-8.

9. Cole C, Wellard S, Mummery J. Problematising autonomy and advocacy in nursing. Nurs Ethics. 2014 Aug;21(5):576-82.

10. Simmonds $\mathrm{AH}$. Autonomy and advocacy in perinatal nursing practice. Nurs Ethics. 2008 May;15(3):360-70.

11. Bu X, Jezewski MA. Developing a mid-range theory of patient advocacy through concept analysis. J Adv Nurs. 2007 Jan;57(1):101-10.

12. Hanks RG. Development and testing of an instrument to measure protective nursing advocacy. Nurs Ethics. 2010 Mar;17(2):255-67.

13. Beaton DE, Bombardier C, Guillemin F, Ferraz MB. Guidelines for the process of cross-cultural adaptation of self-report measures. Spine. 2000 Dec;25(24):3186-91. 14. Dalmolin GL, Lunardi VL, Lunardi GL, Barlem ELD, Silveira RS. Moral distress and Burnout syndrome: are there relationships between these phenomena in nursing workers? Rev. Latino-Am. Enfermagem. 2014 Feb;22(1):35-42.

15. Mahlin M. Individual patient advocacy, collective responsibility and activism within professional nursing associations. Nurs Ethics. 2010 Mar;17(2):247-54

16. Hanks RG. The lived experience of nursing advocacy. Nurs Ethics. 2008 Jul;15(4):468-77.

17. Thacker KS. Nurses' advocacy behaviors in end-oflife nursing care. Nurs Ethics. 2008 Mar; 15(2):174-85.
18. O'Connor T, Kelly B. Bridging the Gap: a study of general nurses' perceptions of patient advocacy in Ireland. Nurs Ethics. 2005 Sep;12(5):453-67.

19. Barlem ELD, Ramos FRS. Constructing a theorical model of moral distress. Nurs Ethics. 2014. In press. pii: 0969733014551595. [Epub ahead of print]. 